\title{
Formation of foreign-language communicative competence at the scientific language lessons
}

\section{Formación de competencia comunicativa extranjera en clases sobre el estilo científico del habla}

\author{
Nikitina Ekaterina \\ Peoples' Friendship University of Russia (RUDN University), Moscow, Russian Federation \\ ORCID: https://orcid.org/0000-0002-3845-6391 \\ Zyryanova Svetlana \\ Peoples' Friendship University of Russia (RUDN University), Moscow, Russian Federation \\ ORCID: https://orcid.org/0000-0002-7993-7052 \\ Morozova Svetlana \\ Sergo Ordzhonikidze Russian State University for Geological Prospecting, Moscow, Russian \\ Federation \\ ORCID: https://orcid.org/0000-0003-2955-8545
}

Received 07-07-20 Revised 09-25-20 Accepted 01-13-21 On line 01-25-21

*Correspondencia

Email: NikitinaEkaterina@gmail.com
Citar como:

Nikitina, E., Zyryanova, S., \& Morozova, S. (2021). The hermit character as a new type of character in realistic prose by Maxim Gorky. Propósitos y Representaciones, 9 (SPE2), e947. Doi: http://dx.doi.org/10.20511/pyr2021.v9nSPE2.947 


\section{Summary}

The article proves that formation of foreign-language communicative competence is one of the core objectives of teaching Russian as a foreign language. The author proves that foreignlanguage communicative competence is a complex construct which includes linguistic, substantive, and pragmatic competences. Preparatory departments are to create an educational model that would provide formation of foreign-language communicative competence.

Keywords: Foreign-language communicative competence, linguistic competence, substantive competence, pragmatic competence.

\section{Resumen}

El artículo demuestra que la formación de competencia comunicativa extranjera es una de las tareas principales de aprender ruso como el idioma extranjero. Se demuestra que la competencia comunicativa extranjera es una construcción compleja que incluye las competencias lingüísticas, temáticas y pragmáticas. La tarea de las facultades preparatorias es crear un modelo educativo que contribuya a la formación de las competencias comunicativas extranjeras.

Palabras clave: Competencia comunicativa en lengua extranjera, competencia lingüística, competencia sustantiva, competencia pragmática.

\section{Introducción}

Foreign students start learning Russian as a foreign language at preparatory departments. This is an important stage where the professors of preparatory departments are to, on the one hand, help their students adapt to linguistically diverse background and, on the other hand, to prepare the students for the entering the university with the chosen speciality. The main objective for the foreign students from preparatory departments is to learn Russian as a foreign language at the B2 level and Russian as the vocation-related language, which will help to achieve educational and professional goals in the future.

Communicative competence becomes especially important for the future specialists in the mass media area. For instance, future journalists learn how to work for newspapers and magazines, in the news agencies and online media, on TV and radio. The obtained communicative competence has a significant impact on the success in comprehension of educational program and future career. That is why the formation of communicative competence is crucial even at preparatory departments.

\section{Background}

The development of foreign-language communicative potential of students in the process of studying the scientific language is a complex multi-level process which consists of 3 elements: communicative abilities, communicative skills and communicative competences. During the educational process the preparatory department students are to be prepared for communication in Russian, orally and in writing, to achieve interpersonal and intercultural goals. Moreover, the students are to be ready to use Russian as a means of achieving educational and professional goals.

The analyzed scientific literature has demonstrated that foreign-language communicative competence in the context of teaching foreign languages was researched by Popova N.V., 
Kogan M.S. \& Vdovina E.K. (2018) ${ }^{1}$, Zavyalov V.V. (2018), Solomatina A.G. (2018), and others. The scholars have made an unquestionable contribution to the methodology of teaching foreign languages, but there is still no system of practical exercises which would intensify the formation of foreign-language communicative competence.

\section{Discussion}

\section{language}

\section{Methodological basis of communicative approach to the teaching of vocation-related}

As the ability to use communicative techniques, communicative competence, plays a key role in language training. N.I. Gez reckons that communicative competence requires linguistic competence and includes data on the language, the ability to relate linguistic means to communicative goals, as well as the ability to communicate, according to social guidelines and communicative relevance (Gez 1985, p. 67-72).

Linguistic competence is a basic communicative competence. It is "linked to the linguistic aspect of the communicative units of language", "providing the formation of grammatically correct and meaningful utterances..." (Izarenkov 1990, p. 56-57).

To build linguistic competence, foreign students are to do the exercises related to reading of new words and word combinations and looking them up, as well as activating mental processes. For example, the future journalists are supposed to explain meanings of words without a dictionary.

Lexical and grammatical skills and competences are developed through the exercises aimed at the formation of word combinations. The introductory course contains the grammatical material which explains the use of subjects after transitive verbs and predicative subjects.

The use of grammatical constructions influences foreign-language communicative competence as well. The introductory unit «Определение журналистики. Функции и принципы журналистики» suggests that foreign students should learn the following grammatical constructions, such as "definition": что (И.п.) - это что (И.п.), что (И.п.) представляет собой что (В.п.), что (И.п.) является чем (Т.п.).

The expertise in communicative skills, abilities and competences is crucial for an effective activity. Communication is closely linked to the notion of information. While information is a sum of knowledge, skills and competences we obtain over the course of our life, communication is related to their transmission. However, an effective communication would not suffice for it. The higher linguistic competence may still cause misunderstanding and even a conflict between the native speakers and a foreigner. "The matter is that even speaking the same language, people may misunderstand each other, often due to cultural differences" (Popova, Kogan \& Vdovina 2018, p. 30).

Foreign-language communicative competence requires appropriate utterances. A student should be able to make a precis of the text and get the message of what the professor and other participants of the communication process. Such an approach "also presupposes controlling linguistic competence, i.e. controlling the level of grammatical correctness and use of system of language" (Vlasova, Alekseeva \& Barabanova 1990, p. 27). Since this stage is related to the formation of pragmatic competence, which presupposes "understanding the correspondences between communicative intentions and their expression; understanding the correspondences between the variants of utterances with the same intention and the circumstances of communication; the ability to express a communicative intention by selecting an appropriate communicative act according to the situation and the course of communication" (Izarenkov 1990, p. 56-57). The work with big meaningful texts is preceded by the work with microtexts.

\footnotetext{
${ }^{1}$ Popova, N.V., Kogan, M.S., Vdovina, E.K. (2018) Content and Language Integrated Learning (CLIL) as a methodological mainstreaming of interdisciplinary linkages in technical universities. Tambov University Review. Series: Humanities, Vol. 23, No 173, Russia, Tambov: pp. 29-42
} 
The work with microtexts facilitates the formation of substantive competence which is linked to "the contents of utterances" and "provides obtain the knowledge of the subject concerned; pragmatic competence reflects the communicative intentions of a speaker, helping them to develop the skill of using utterances in the certain communicative context according to the communicative intentions and situations" (Izarenkov 1990, p. 56-57).

Therefore, teaching a vocation-related language is communication-oriented. Those who organize educational process are to create completely new professional modules of teaching scientific language which would help forming foreign-language communicative competence.

Practical experience of forming foreign-language communicative competence at the scientific language lessons based on the example of an introductory lesson "The definition of journalism. The functions and principles of journalism" / «Определение журналистики. Функции и принципы журналистики»

As we can see, formation of foreign-language communicative competence is the most important task the professors are to do when teaching Russian as a foreign language. As professional activity of the "Journalism" speciality foreign students is related to highly developed communicative skills, such skills should be developed at the scientific language lessons.

The example of a scientific language lesson is a structured system of exercises aimed at forming communicative competence in foreign students.

Урок «Определение журналистики. Функции и принципы журналистики»

Задание 1. а) Прочитайте новые слова и словосочетания. Посмотрите в словаре их значения.

1) деятельность (общественная, производственная, журналистская)

2) произведение

3) сбор (чего?) материала (собирать - собрать)

4) обрабатывать - обработать (что? В.п.) информацию; обработка (чего?) информации

5) публиковать - опубликовать (что? В.п.); опубликование (чего?)

6) описывать - описать (что? В.п.) событие

7) анализировать - проанализировать (что? В.п.) произведение

8) составлять - составить (что? В.п.) журналистский материал

9) распространять - распространить (что? В.п.) новости; распространение (чего?) новостей

\section{0) доступный} словаря.

б) Прочитайте толкование слов и словосочетаний. Попробуйте понять их без

11) печатное издание $=$ газета, журнал

12) адресат информации = получатель информации: читатель, зритель, слушатель

13) раздел (чего? учебника) = часть момента

14) актуальный; актуальная информация = информация, важная для настоящего

Задание 2. Напишите словосочетания прилагательных с существительными.

Модель: печатный ... (издания) - печатные издания

1) журналистский ... (материал, произведение, текст)

2) производственный ... (деятельность, процесс)

3) общественный ... (жизнь, мнение)

4) актуальный ... (вопрос, проблемы, новость)

5) доступный ... (источник информации, помощь) 
ЗАПОМНИТЕ! После переходных глаголов существительное стоит в винительном падеже, а после отглагольных существительных - в родительном.

Например: изучать (что? В.п.) науку - изучение (чего? Р.п.) науки

Задание 3. Напишите словосочетания. Поставьте существительные в форму винительного или родительного падежа.

Модель: распространять (важная новость) - распространение...

распространять важную новость - распространение важной новости

1) собирать (журналистский материал; актуальная информация) - сбор...

2) распространять (печатные издания; печатная продукция) - распространение...

3) обрабатывать (новый материал, текст статьи) - обработка...

4) опубликовать (литературное произведение, журналистский текст, статья об экономике) - опубликование...

5) формировать (общественное мнение) - формирование...

ЗАПОМНИТЕ КОНСТРУКЦИИ!

ЧТО (И.п.) - это ЧТО (И.п.)

Газеты и журналы - это печатные издания.

= ЧТО (И.п.) представляет собой ЧТО (В.п.)

Газеты и журналы представляют собой печатные издания.

= ЧТО (И.п.) является ЧЕМ (Т.п.)

Газеты и журналы являются печатными изданиями.

Задание 4. а) Передайте информацию по-другому. Используйте конструкцию с глаголом «представлять собой».

1) Журналистика - это общественная и производственная деятельность по сбору и распространению информации. 2) Социально значимая информация - это актуальная информация, которая интересует многих людей. 3) Печатные издания, программы радио и телевидения - это каналы массовой информации. 4) Продукция журналистской деятельности - это произведения, из которых составляют номера газет и журналов, программы радио и телевидения.

Б) Передайте информацию по-другому. Используйте конструкцию с глаголом «являться».

1) Читатели, зрители и слушатели - это адресаты информации. 2) Информация, важная для настоящего момента, - это актуальная информация. 3) Телепрограмма, которая выходит каждый день, - это ежедневная телепрограмма. 4) Журнал, который выходит один раз в неделю, - это еженедельный журнал. 5) Печатное издание, которое выходит один раз в месяц, - это ежемесячное печатное издание.

ЗАПОМНИТЕ КОНСТРУКЦИЮ!

ЧТО (И.П.) в ХодиТ в состав ЧЕГО (Р.П.)

Понятие «деятельность по сбору и обработке информации» входит в состав определения журналистики.

Задание 5. Прочитайте микротексты и ответьте на вопросы.

1) В состав определения журналистики входит понятие «деятельность по сбору и обработке информации». 
Ежедневно мы слушаем, смотрим или читаем информацию о разных событиях и людях. Эту информацию собирает журналист и пишет журналистские материалы.

Журналист не только собирает информацию, но и обрабатывает ее, анализирует, выбирает главное, проверяет правдивость и точность информации и решает, как сообщить ее читателям или зрителям.

Такая работа журналиста называется деятельностью по сбору и обработке информации.

- Что значит «деятельность по сбору и обработке информации»?

2) Также в состав определения журналистики входит понятие «периодическое распространение информации».

Журналисты собирают материалы, обрабатывают их и распространяют информацию: публикуют в печатных изданиях, сообщают по радио, телевидению и с помощью Интернета. Так читатели, зрители, слушатели узнают о событиях в стране и в мире, т. е. информация становится доступной для адресата информации.

Если программа или печатное издание выходит каждый день, то журналист должен находить новую информацию, обрабатывать ее и сообщать читателю ежедневно. Если газета представляет собой еженедельное или ежемесячное издание, то журналисты должны подготавливать материалы еженедельно или ежемесячно. Периодическое распространение информации - это распространение информации через определенный период времени, который зависит от типа издания или программы (ежедневная программа, ежемесячный журнал и т.п.)

- Что представляет собой «периодическое распространение информации»?

3) Информация, которую собирает и публикует журналист, должна представлять собой социально значимую информацию. Она должна быть актуальной и интересовать многих людей, т.е. общество.

- Что такое «социально значимая информация»?

Журналистика - это общественная и производственная деятельность по сбору, обработке и периодическому распространению актуальной социальной информации с помощью каналов массовой информации (печатных изданий, программ радио и телевидения).

4) Также журналистикой называется продукция журналистской деятельности. Продукция журналистской деятельности представляет собой произведения, из которых составляют номера газет и журналов, программы радио и телевидения.

5) Наконец, журналистикой называется раздел научного знания и образования.

- Что такое журналистика?

Задание 6. Задайте вопросы к предложениям.

1) Журналист выбирает главное, проверяет правдивость и точность информации и решает, как сообщить её читателям или зрителям.

2) Информация должна быть актуальной и социально значимой.

3) Это печатные издания, программы радио и телевидения.

4) Это произведения, из которых составляют номера газет и журналов, программы радио и телевидения.

5) Раздел научного знания и образования. 
Задание 7. Прочитайте диалог и ответьте на вопросы.

Рамон (Венесуэла): - Из текста я понял, что журналист должен все время искать и находить актуальную социально значимую информацию.

Мария (Франция): - А что такое актуальная социально значимая информация?

Диана (Корея): -Это информация, которая интересует читателей, слушателей и зрителей в данный момент. Эта информация должна интересовать не одного человека, а многих людей, т.е. общество.

Мануэль (Испания): - Но собирать информацию - это не самое трудное. Журналист должен обрабатывать эту информацию: проверять ее, находить главное, писать журналистский материал.

Лю Дунь (Китай): - Когда журналистский материал готов, его публикуют в газетах, в журналах, в Интернет-изданиях. Еще могут показать по телевидению или сообщить по радио. Так происходит распространение информации.

Вахид (Иран): - Газеты, журналы, программы радио и телевидения - это каналы массовой информации.

Лю Дунь (Китай): - А работа журналиста называется производственной деятельностью, потому что журналист производит продукцию, как рабочие на заводах и фабриках.

1) Что Диана ответила Марии на вопрос об актуальной социально значимой информации?

2) Что рассказал Мануэль о работе журналиста с информацией?

3) Как объяснила Лю Дунь, что такое распространение информации?

4) Как вы поняли, что такое каналы массовой информации?

5) Почему работа журналиста называется производственной деятельностью?

Задание 8. Прочитайте названия разделов газеты «Аргументы и фактыл». Скажите, какую информачию публикуют в каждом разделе.

ПОЛИТИКА. ОБЩЕСТВО. ДЕНЬГИ. КУЛЬТУРА. СПОРТ. КУХНЯ. ДОСУГ. МНЕНИЯ. НЕДВИЖИМОСТЬ.

Задание 9. а) Заполните схему. Расскажите, в чем заключаются главные задачи журналиста и журналистики.

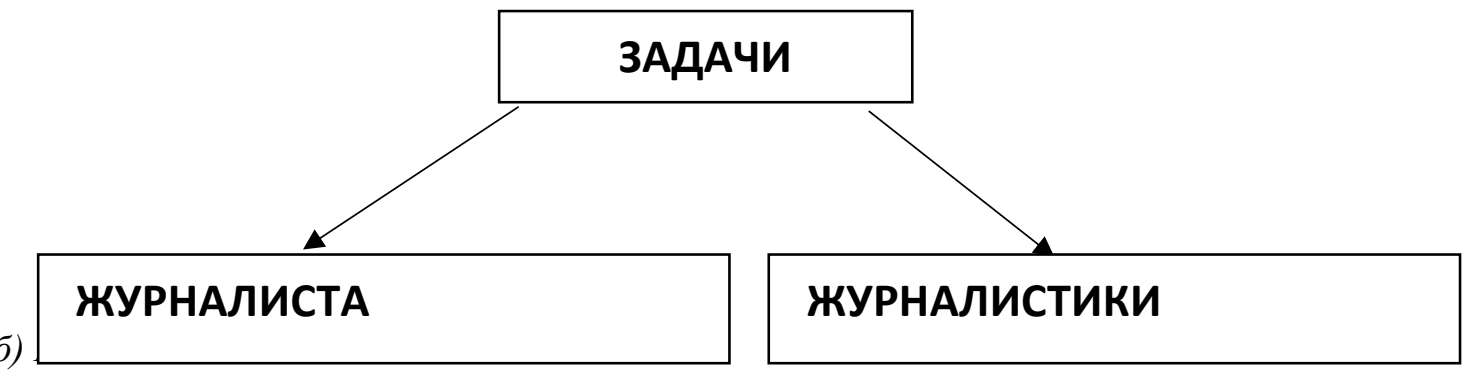

Журналисты (...) читателя, зрителя, слушателя о событиях, (...) актуальные, интересные и понятные произведения.

Журналистика (...) сознанием и поведением адресата массовой информации. Она не только (...) различные события и факты, но и (...) на отношение общества к этим событиям и фактам, (...) общественное мнение.

Глаголь:: влиять, информировать, описывать, писать, управлять, формировать.

Задание 10. а) Прочитайте новые слова. Посмотрите в словаре их значения.

1) функция

2) устанавливать - установить (что? В.п.) связь, отношения

3) положительный

4) критический

5) правовой (правовые идеи) 
6) нравственный (нравственные идеи)

7) религиозный (религиозные идеи)

б) Прочитайте толкование слов и словосочетаний. Попробуйте понять их без словаря.

8) совокупность (чего?) = группа, сумма

9) публикация = то, что опубликовано, напечатано

10) взгляд = мнение

11) пропаганда = распространение различных идей и взглядов

12) массовая аудитория = читатели газет и журналов, радиослушатели, телезрители, пользователи Интернета и др.

13) выполнять - выполнить (что? В.п.) работу = делать

14) художественный; художественные материалы $=$ которые имеют связь $\mathrm{c}$ искусством.

\section{ЗАПОМНИТЕ!}

Отглагольные существительные могут быть образованы с помощью суффиксов -енн, -анн.

Например: изменять - изменить (что?) планы изменение (чего?) плњнов

создавать - создать (что?) армию создание (чего) армии

Задание 11. а) Прочитайте глаголь и отглагольные существительные

\begin{tabular}{|l|l|}
\hline устанавливать - установить (что?) & установление (чего?) \\
\hline проводить - провести (что?) & проведение (чего?) \\
\hline выполнять - выполнить (что?) & выполнение (чего?) \\
\hline управлять (чем?) & управление (чем?) \\
\hline публиковать - опубликовать (что?) & опубликование (чего?) \\
\hline формировать - сформировать (что?) & формирование (чего?) \\
\hline $\begin{array}{l}\text { информировать } \\
\text { проинформировать (кого?) }\end{array}$ & информирование (кого?) \\
\hline влиять - повлиять (на что?) & влияние (на что?) \\
\hline
\end{tabular}

Запомните, как образуются существительные от некоторых глаголов:

\begin{tabular}{|l|l|}
\hline обрабатывать - обработать & обработка(чего?) \\
\hline собирать - собрать (что?) & сбор (чего?) \\
\hline выбирать - выбрать (что?) & выбор (чего?) \\
\hline защищать - защитить (что?) & защита (чего?) \\
\hline участвовать (в чем?) & участие (в чем?) \\
\hline
\end{tabular}

б) Замените глагольные словосочетания именными.

Модель: собирать материал - сбор материала

1) изменить мнение - ..; 2) устанавливать связи - ..; 3) опубликовать критическую статью - ..; 4) проводить свободное время - ..; 5) выполнять различные функции -...; 6) управлять сознанием и поведением людей - ..; 7) информировать адресата - ..; 8) влиять на работу правительства - ..; 9) выбрать профессию - ..; 10) участвовать в конкурсе - ... .

Задание 12. а) Прочитайте и запишите новую модель предложений.

\section{ЧТО (И.п.) связано С ЧЕМ (Т.п.)}

Работа журналиста связана со сбором и распространением информации. 
он связан

она связана

оно связано

они связаны падежа.

б) Раскройте скобки. Поставьте существительные в форму творительного

1) Главная задача журналистики связана с... (формирование общественного мнения). 2) Основная задача журналиста связана с... (информирование читателей, зрителей, слушателей) о событиях. 3) Возникновение и развитие журналистики связаны с... (жизнь общества). 4) Изменение расписания связано с... (начало нового семестра). 5) Выбор темы статьи связан с... (актуальность этой темы).

Задание 13. Прочитайте микротексты и ответьте на вопросы.

\section{Функции журналистики}

1) Функции журналистики - это совокупность социальных ролей, которые она выполняет.

Основной функцией журналистики является коммуникативная функция. Журналистика устанавливает связь с массовой аудиторией и социальными институтами (государством, правительством, армией, церковью и др.)

Организаторская функция журналистики связана с ее влиянием на деятельность социальных институтов через положительные или критические публикации. Например, критические публикации о работе правительства могут изменить работу правительства и даже его состав. Так с помощью журналистики формируется, развивается и улучшается система социальных институтов.

Журналистика выполняет идеологическую функцию. Идеология - это система взглядов и идей: политических, экономических, правовых, нравственных, философских, религиозных. Журналистика занимается пропагандой различных идей, формирует идеологические взгляды людей и создает общественное мнение, которое влияет на общественный выбор и массовое поведение.

- Что представляют собой функции журналистики?

- В чем заключается коммуникативная функция журналистики?

- Как журналистика выполняет организаторскую функцию?

- С чем связана идеологическая функция журналистики?

2) Также журналистика выполняет культурно-образовательную, рекламносправочную и рекреативную функции.

Культурно-образовательная функция журналистики связана с пропагандой и распространением культуры и знаний в обществе. Эту функцию выполняют художественные программы и научно-популярные материалы. Рекламно-справочная функция журналистики заключается в информировании массового адресата по различным вопросам. Рекреативная функция (от лат. recreatio «восстановление», «отдых») создает условия для отдыха, интересного проведения свободного времени. Эту функцию выполняют различные телешоу, конкурсы, детективы и т.п.

Обычно журналистское произведение выполняет несколько функций, потому что такое произведение является более интересным и, значит, более популярным.

- С чем связаны культурно-образовательная, рекламно-справочная и рекреативная функции журналистики?

- Какую функцию выполняют художественные программы и научно-популярные материалы?

- Какую функцию выполняют различные телешоу, конкурсы и детективы?

- Расскажите о статье, которую вы прочитали, или телепрограмме, которую посмотрели недавно. Скажите, какие функции она выполняет? 
Задание 14. Составьте предложения. Соедините информачию из правой и левой колонок таблищьы.

\begin{tabular}{|c|c|}
\hline Коммуникативная функция журналистики & пропаганда и распространение \\
\hline заключается в... & культуры и знаний в обществе \\
\hline $\begin{array}{l}\text { Организаторская функция журналистики } \\
\text { связана с ... }\end{array}$ & $\begin{array}{l}\text { создание условий для отдыха, интересного } \\
\text { проведения свободного времени }\end{array}$ \\
\hline $\begin{array}{l}\text { Идеологическая функция журналистики } \\
\text { связана с... }\end{array}$ & $\begin{array}{l}\text { установление связи с массовой аудиторией } \\
\text { и социальными институтами }\end{array}$ \\
\hline $\begin{array}{l}\text { Культурно-образовательная } \\
\text { журналистики заключается в... }\end{array}$ & $\begin{array}{l}\text { пропаганда различных идей и взглядов, } \\
\text { формирование общественного мнения }\end{array}$ \\
\hline $\begin{array}{l}\text { Рекламно-справочная } \\
\text { журналистики связана с... }\end{array}$ & $\begin{array}{l}\text { влияние журналистики на деятельность } \\
\text { социальных институтов }\end{array}$ \\
\hline $\begin{array}{l}\text { Рекреативная функция журналистики } \\
\text { заключается в... }\end{array}$ & $\begin{array}{l}\text { информирование адресата информации по } \\
\text { различным вопросам }\end{array}$ \\
\hline
\end{tabular}

Задание 15. а) Прочитайте и проанализируйте предложения.

Рекламно-справочная функция журналистики связана с информированием людей по различным вопросам. $=$

Рекламно-справочная функция журналистики связана с тем, что журналистика информирует людей по различным вопросам.

Идеологическая функция журналистики заключается в распространении различных идей и взглядов.

Идеологическая функция журналистики заключается в том, что журналистика распространяет различные идеи и взгляды.

б) Передайте информацию по-другому. Используйте конструкиии, которые даны $в$

1) Организаторская функция журналистики связана с влиянием на деятельность социальных институтов. $=\ldots$

2) Культурно-образовательная функция журналистики связана с распространением культуры и знаний в обществе. $=\ldots$

3) Коммуникативная функция журналистики заключается в установлении контакта с массовой аудиторией. $=\ldots$

4) Центральная задача журналиста заключается в информировании читателей, зрителей, слушателей о событиях. $=\ldots$

5) Главные задачи журналистики заключаются в управлении сознанием и поведением людей и в формировании общественного мнения. $=\ldots$

Задание 16. Прочитайте новые слова. Посмотрите в словаре их значения.

1) принцип

2) количество (кого?) человек

3) сотрудничество

4) представлять - представить (что? В.п.) интересы народа

5) выражать - выразить (что? В.п.) свое мнение.

Задание 17. Прочитайте микротекст и ответьте на вопросы.

\section{Принципы журналистики}

Журналистика может выполнять все свои функции, только если работают принципы (общие правила) журналистики. 
Основным принципом журналистики является принцип партийности. Данный принцип совсем не означает связь с определенной политической партией. Он заключается в том, что журналистика выражает интересы какой-нибудь чисти общества, его определенной группы (или всего человечества как одной большой группы).

Принцип народности заключается в том, что журналистика должна представлять общенародные интересы. Но народ состоит из многих групп, интересы которых могут быть различными. Значит, журналист должен бороться за развитие и объединение тех общественных групп, которые заинтересованы в прогрессивном развитии страны.

Принцип правдивости связан с тем, что журналист распространяет только информацию, в точности и правдивости которой он уверен и источник которой он хорошо знает.

Принцип массовости связан с тем, что издания и программы влияют на огромное количество людей. Журналист должен всегда устанавливать связь со своей аудиторией, чтобы понимать, что ее интересует. Журналистские материалы должны быть составлены на простом и доступном языке и являться актуальными для массового адресата.

Принцип патриотизма заключается в том, что журналист в своих публикациях должен защищать интересы родной страны, ее культуру, исторические памятники, язык и традиции.

Принцип демократизма связан с участием журналистики в государственной жизни. Журналистика выступает от имени народа, а также дает возможность каждому человеку выразить свое мнение. Через журналистику народ может участвовать в делах государства, влиять на работу правительства.

Принцип интернационализма заключается в том, что журналист всегда должен помнить о равенстве всех народов, помогать устанавливать отношения дружбы и сотрудничества между народами.

- В чем заключается принцип партийности?

- С чем связан принцип народности?

- Какой принцип связан с распространением только точной и правдивой информации?

- Какой принцип связан с защитой интересов своей страны, ее культуры, исторических памятников, языка и традиций?

- Что значит принцип демократизма?

- Какой принцип связан с влиянием изданий и программ на огромное количество людей?

- С чем связан принцип интернационализма?

To sum up, the example of the lesson "The definition of journalism. The functions and principles of journalism" is a system of interrelated exercises aimed at forming foreign-language communicative competence in foreign students. Taking into consideration the specifics of the future profession is a necessary condition of the educational process.

\section{Conclusiones}

The research leads to the following conclusions:

1) The formation of foreign-language communicative competence in "Journalism" speciality foreign students is one of the key objectives of teaching Russian as a foreign language at preparatory departments.

2) Foreign-language communicative competence is a complex multi-level process which consists of linguistic, substantive, and pragmatic competences. Its formation starts from the beginning of study at preparatory departments.

3) Being the basis of foreign-language communicative competence, linguistic competence is aimed at building the skills of making grammatically correct utterances. The development of substantial competence at the scientific language lessons is linked to building the skills of 
formulating adequate contents of the utterances related to the subject area. Pragmatic competence provides building the skills of selecting the appropriate linguistic means according to the situation.

\section{Referencias}

Adonina, L.V., Adonin, R.F. \& Fisenko, O.S. (2017) Cognitive trend in modern science of language: materials for the organization of academic work in classes of the philological profile. Language and Personality in a Multicultural Space. Digest of articles. Edited by I.N. Avdeeva, Russia, Moscow, 134-143

Gez, N.I. (1985) Formation of communicative competence as an object of foreign methodological study. Inostrannye yazyki v shkole. No 2,18-36

Izarenkov, D.I. (1990) The basic components and the formation of communicative competence at the advanced level of teaching non-linguistic specialty students. Russian Language Abroad. No 4, 56-57

Kargina, N.V., Ficenko, O.S. \& Polyanskaya E.N. (2017) Technology of social manament in organization in the Russia federation: the theoretical aspect The Turkish online Journal of Design Art and Communication TOJDAC, December 2017 Special Edition, 19701979

Nikitina, E.V. \& Rubtsova, D.N. (2017) The basics of journalism. 1st sertification level. Russia, Moscow, 118

Popova, N.V., Kogan, M.S. \& Vdovina, E.K. (2018) Content and Language Integrated Learning (CLIL) as a methodological mainstreaming of interdisciplinary linkages in technical universities. Tambov University Review. Series: Humanities, Vol. 23. No 173. Russia, Tambov, 29-42

Solomatina, A.G. (2018) Teaching Russian as a foreign language to agrarian specialty students on the basis of CLIL model for professional purposes. Tambov University Review 177. Series: Humanities. No 173. Russia, Tambov, 49-57

Vlasova, N.S., Alekseeva, N.N. \& Barabanova, N.R. (1990) Practical methodology of teaching Russian as a foreign language. Level Al. Russia, Moscow, 167

Zavyalov, V.V. (2018) Models of teaching a foreign language to non-linguistic specialty students for professional purposes. Derzhavin Forum. No 6, 175-184

\section{Financiamiento:}

* This paper has been support by the RUDN University Strategic Academic Leadership Program. 